\title{
VIEWPOINT \\ Reflux disease - reflux esophagitis: Unanswered questions and problems
}

G.N.J. TYTGAT, MD, PHD

O ASTROESOPHAGEAL REFLUX DISEASE (GERD) IS COMMON in the western world. However few data are available with respect to its precise prevalence in the community. Symptoms suggestive of reflux disease are often mixed with other symptoms comprising the dyspepsia syndrome. Recently, the first attempts in trying to dissect the various subentities within the dyspepsia syndrome have been published. Major subentities are: ulcer-like dyspepsia, dysmotility-like dyspepsia, reflux-like dyspepsia, aerophagia and a miscellaneous subgroup (1). Which percentage of the patients with dyspepsia belongs to the reflux-like subentity is unknown. Information is equally lacking with respect to the question, which percentage of those with reflux-like dyspepsia truly have genuine GERD measured by $24 \mathrm{~h} \mathrm{pH}$ monitoring or endoscopic evidence of reflux esophagitis.

When a patient first presents to the family physician, it is reasonable to attempt a therapeutic trial before deciding whether this patient needs further investigation. This is especially so for the younger patient population and when 'alarming symptoms' such as dysphagia, weight loss, symptoms of anemia, etc, are absent. How such a therapeutic trial should be carried out most appropriately is unknown, but it is usually recommended that antacids are the therapy of choice. One may question whether this is correct, especially when the symptoms truly suggest 'typical' reflux disease such as 'typical' heart-

University of Amsterdam, Amsterdam. Netherlands Correspondence and reprints: Professor G. N. Tytgat, Academisch Ziehenhuis Bij De Universiteit van Amsterdam, Academisch Medisch Centrum, Meibergdreef 9, 1105 AZ, Amsterdam Zuidoost. Netherlands

Received for publication September 15, 1988. Accepted September 19, 1988 burn (an acid sensation starting in the upper epigastric area or retrosternal area with retrosternal ascending characteris. tics), nocturnal heartburn, acid regurgitation, etc. It would appear equally logical to prescribe an $\mathrm{H}_{2}$ receptor antagonist or any of the other drugs which have been shown to be effective both symptomatically and objectively in relieving reflux symptoms and healing reflux induced mucosal abnormalities. Furthermore, it is not uncommon that patients seek medical attention after having tried intermittent antacid therapy because of insufficient relief of symptoms.

If the response to the therapeutic trial, carried out for four to six weeks, is adequate, meaning that both patient and physician consider the result as satisfactory, then no further diag. nostic work-up is necessary and the patient may be either advised to continue the same therapy for some time or to stop the therapeutic trial.

If, on the other hand, the patient continues to suffer from reflux-like symptoms, especially when nocturnal symptoms also occur or if the symptoms recur rapidly after the therapeutic trial, then it is probably wise to refer the patient for further work-up to document whether there is mucosal damage and if so of which degree. Also, to find out whether the symptoms are truly due to reflux disease if no endoscopic abnormalities are present.

Currently the usual work-up of such patients is to perform endoscopy first and to perform a $24 \mathrm{~h} \mathrm{pH}$ monitoring study if no endoscopic abnormalities are present or if it is difficult to interpret the symptomatology of the patient. For both diagnostic examinations there is considerable debate about how to perform and how to grade the abnormalities.

Many endoscopists still struggle with the criteria upon which 
to diagnose a hiatal hernia. Scoring the degree of abnormality in reflux esophagitis is equally difficult. The diagnosis of a hiatal hernia requires recognition of the squamocolumnar mucosal junction (SCMJ) and the level of the diaphragmatic hiatus. If during quiet respiration and without excessive air insufflation the SCMJ is located more than 2 to $3 \mathrm{~cm}$ above the diaphragmatic impression, then an axial hiatal hernia may be diagnosed. Often the hernia appears as a pouch-like area just below the SCMJ and above the diaphragm. The area of the mucosal junction may appear patulous allowing the endoscopist to look directly through this area straight into the hiatal hernia pouch. After retroflexing the endoscope in the stomach, a space or cupola may become evident around the endoscope as the latter passes through the cardia.

The criteria for reflux esophagitis are usually those presented by Savary and Miller (2). Grade 1 consists of isolated, usually linear streaks or maculate patches; grade 2 is diagnosed when there is early confluence; grade 3 indicates circumferential involvement; and grade 4 stricturing, deep ulceration or columnar metaplasia. Grade 1 may be subdivided into $1 \mathrm{a}$ and $1 \mathrm{~b}$ depending on whether the isolated red maculae or streaks have a fibrinous coat or not. Also, for grade 2 a subdivision into $2 \mathrm{a}$ and $2 \mathrm{~b}$ depends upon the absence or presence of a white fibrinous coat over the erosive defects. One should not consider fine vessel prominence, diffuse erythema, friability, mucosal thickening or irregularity or fuzziness of the SCMJ as a trustworthy indicator of GERD

\section{PROLONGED $\mathrm{pH}$ MONITORING}

There is considerable controversy and debate with respect to prolonged $\mathrm{pH}$ monitoring. What is the best equipment to use for ambulatory $\mathrm{pH}$ recording; glass electrodes or the simple antimony electrodes? Should all circumstances mimick as close as possible the natural situation with respect to food, drink, cigarette smoking, physical exercise, etc, or should the procedure for monitoring be standardized with respect to activities, smoking habits, dietary advice, etc? What is the best way of expressing the results; total percentage of time with $\mathrm{pH}$ less than 4 , recumbent and/or upright acid exposure? Is there a need to use more complex scoring systems? What is the boundary between normal and abnormal?

Sleep, food intake and body position have a major influence on reflux. Reflux episodes occur only during brief intervals of arousal between periods of stable sleep or during prolonged periods of nocturnal wakefulness. Disturbance of normal sleep patterns by the presence of $\mathrm{pH}$ electrode may increase the reflux rate. Esophageal acid exposure also increases substantially in the $3 \mathrm{~h}$ after food. Some patients restrict their food intake substantially during $\mathrm{pH}$ monitoring because of discomfort from the $\mathrm{pH}$ electrode.

The effect of body position on rates of reflux and esophageal acid exposure has been insufficiently studied. It is possible that even minor inaccuracies of electrode position may have a substantial impact on values of esophageal acid exposure. Following reflux episodes the esophageal folds may limit access of acid to the mucosa between the folds and so may cause inhomogeneity of intraluminal $\mathrm{pH}$ at any level. There- fore, the position of the $\mathrm{pH}$ electrode relative to the esophageal folds may be a significant determinant of acid exposure. Furthermore, there are indications that reflux varies not inconsiderably in amount from day to day among normal subjects. There is also considerable intrasubject variability of esophageal acid exposure in patients with reflux disease. There is rising agreement that $\mathrm{pH} 4$ is the best threshold value and that the best sensitivity and specificity is obtained if only esophageal acid exposure and the upright and recumbent body position are taken into account when analyzing ambulatory $24 \mathrm{~h} \mathrm{pH}$ monitoring data. For practical purposes the upper limit of normal or total acid exposure time ( $\mathrm{pH}$ less than 4 ) is $5 \%$. Separation between normal and abnormal will presumably be smallest in endoscopy negative patients. This is important since $\mathrm{pH}$ monitoring is often used especially in endoscopy negative patients with atypical symptoms to determine whether there is normal or abnormal reflux.

\section{ANTIREFLUX MEASURES}

If reflux disease/reflux esophagitis is demonstrated the patient is treated with the usual antireflux measures and lifestyle modifications together with drug therapy. The antireflux measures include elevation of the head of the bed, early evening meal, avoidance of symptom provoking foods or drinks and any acid or hypertonic fluids causing symptoms, weight loss when appropriate and abstinence of smoking, although the evidence to support the latter is rather questionable. Drug therapy usually consists of $\mathrm{H}_{2}$ receptor antagonists, sucralfate and one of the newer prokinetic drugs such as cisapride.

The question of the optimal timing of administration of an $\mathrm{H}_{2}$ receptor antagonist is unsettled. Current wisdom states that dosing at night or after the evening meal is most appropriate. When so administered, $\mathrm{H}_{2}$ receptor antagonists suppress evening and nocturnal acid exposure in the esophagus usually with little remaining acid suppressive activity in the morning. Recently, however, it has been shown by several investigators that day time acid reflux is equally if not more important than nocturnal acid reflux (3). The postprandial hours seem to be particularly important in this regard. If that is true, it would appear to be equally logical to dose the $\mathrm{H}_{2}$ receptor antagonist with or after breakfast. Time of dosing, therefore, should preferentially be adapted to the time of reflux symptoms because day time acid exposure is presumably equally damaging as nocturnal acid exposure if both are of equal duration and severity.

Through many therapeutic studies it has become clear that reflux esophagitis is difficult to heal with the currently available drugs. On average, some 30 to $40 \%$ of patients heal after six to eight weeks' therapy with $\mathrm{H}_{2}$ receptor antagonists, sucralfate and/or cisapride and another 30 to $40 \%$ improve endoscopically. The more severe the reflux esophagitis, the more difficult it is to heal within the same time. In contrast, almost total suppression of acid secretion through omeprazole leads to a much higher percentage of healing, stressing that acid is the dominant factor in reflux disease. While omeprazole is not available in many countries, what is the best therapy at the present time? High dose $\mathrm{H}_{2}$ receptor antagonist given after 
dinner or at night? Given for two, three or more months? Combined with sucralfate during the day or combined with cisapride? Sucralfate as monotherapy? Sucralfate plus cisapride?

We are equally ignorant of how to conduct maintenance therapy in reflux disease. Currently all maintenance trials have failed. The question really is whether it matters that some slight aggravation of reflux damage recurs in the esophagus provided we can detect those patients where the disease, when poorly controlled, ultimately will lead to stricturing, deep ulceration or development of a columnar lined esophagus. Unfortunately, at present, no such indicators have been discovered which are clinically useful. It is to be expected that very powerful acid suppressing drugs such as the $\mathrm{H}^{+} / \mathrm{K}^{+}$-ATPase proton inhibitors will become available for clinical use. In all probability administration will be limited to a limited period of time in view of the potential undesirable effect of stimulation of ECL cell proliferation. How then should maintenance therapy be conducted after initial healing with omeprazole: High dose $\mathrm{H}_{2}$ receptor antagonists? Combined therapy with sucralfate or cisapride? Will the indications for surgery change with the availability of potent $\mathrm{H}^{+} / \mathrm{K}^{+}$-ATPase inhibitors? Will the need for antireflux surgery diminish to the same extent as what has been seen in peptic ulcer disease?

It is obvious because of the many unanswered questions, that reflux disease/reflux esophagitis is still marred by a high degree of ignorance both with respect to pathogenesis and to therapy. More judicious use of endoscopy and of ambulatory $\mathrm{pH}$ monitoring may perhaps be helpful in further unravelling the most important aspects of pathogenesis. Availability of more powerful acid suppressive, mucosa protective and motility modulating drugs will hopefully allow better medical control of the disease and allow more judicious use of antireflux surgery to cut down the number of failed surgical interventions.

\section{REFERENCES}

1. Colin-Jones DG and members of the working party. Management of dyspepsia: Report of a working party. Lancet 1988;i:576-9.

2. Savary M, Miller G. The esophagus. Handbook and Atlas of Endoscopy: Solothurn Gassman AG, 1978:135-42.

3. De Caestecker JS, Blackwell JN, Fryde A, Heading RC. Daytime gastro-oesophageal reflux is important in oesophagitis. Gut 1987;28:519-26. 


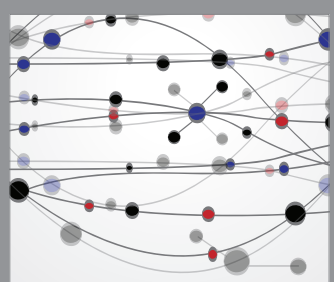

The Scientific World Journal
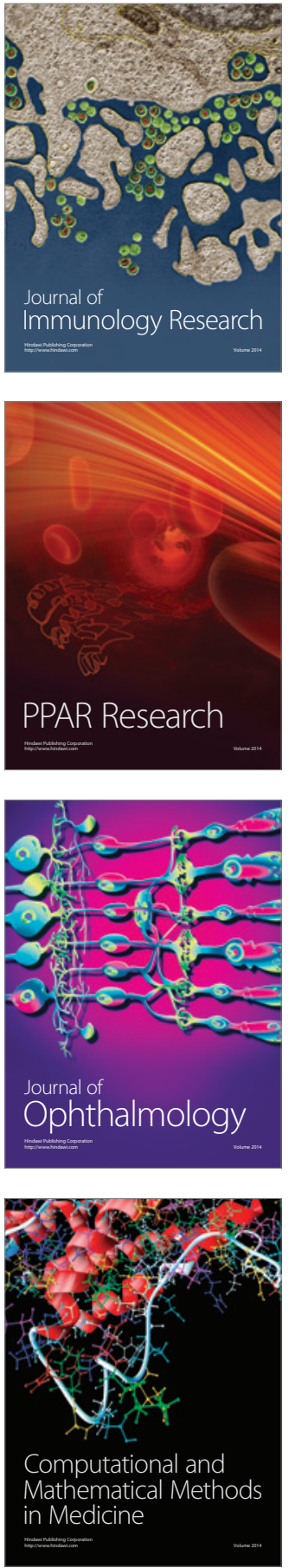

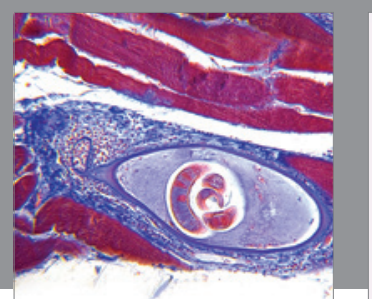

Gastroenterology Research and Practice

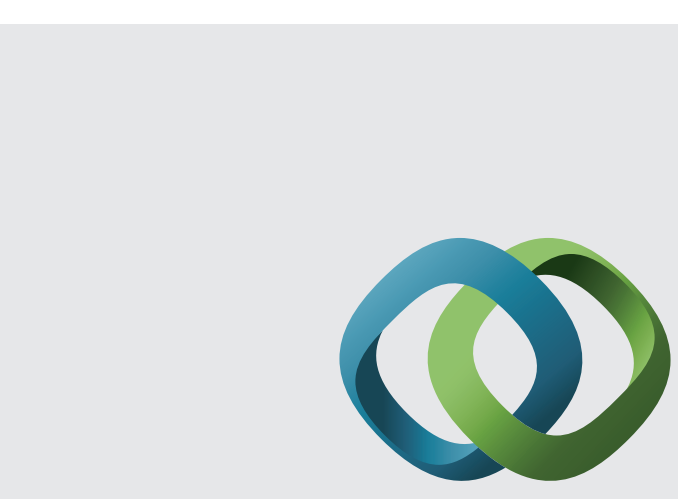

\section{Hindawi}

Submit your manuscripts at

http://www.hindawi.com
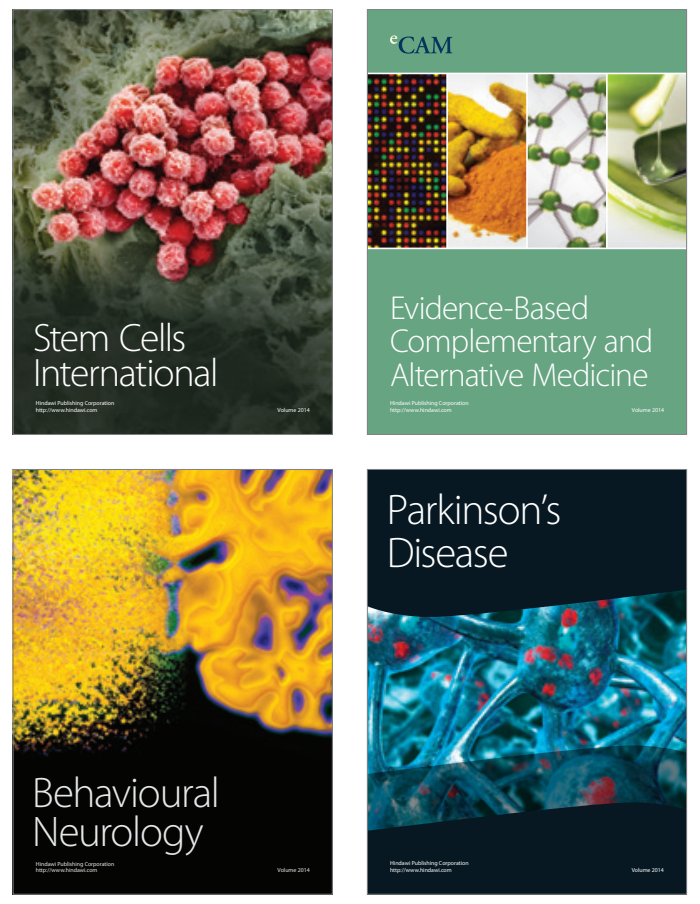
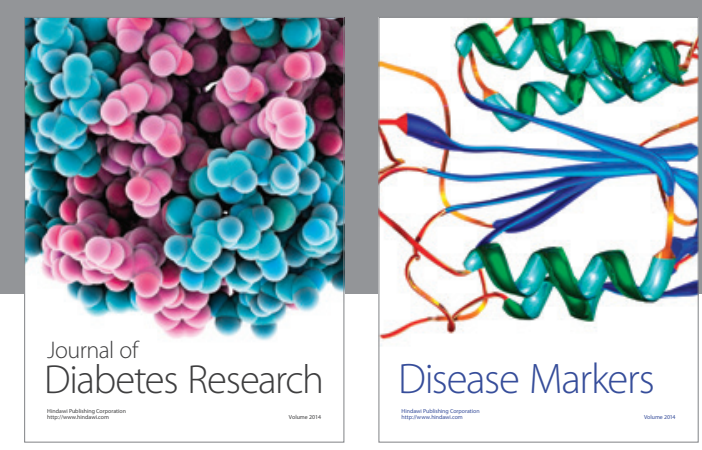

Disease Markers
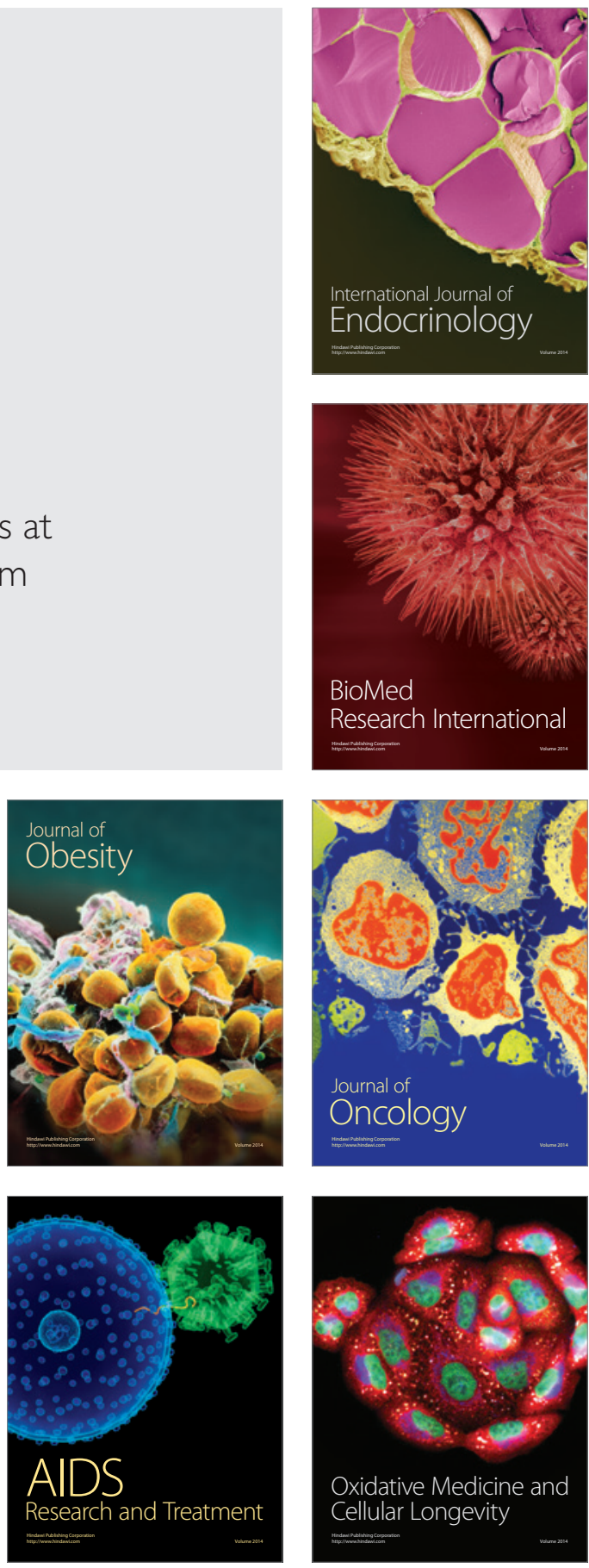